\title{
Exploration of the Teaching Reform of Integrating Pathology Classroom Into "Course Ideology and Politics"
}

\author{
Ningbo Huang
}

Ningxia Medical University, Yinchuan 750001, Ningxia

Abstract: Pathology is an important bridge between basic medicine and clinical medicine, and it plays an irreplaceable role in medical professional courses. With the continuous development of society, there are more requirements for medical students. In addition to solid basic theoretical knowledge and practical skills, students should also have good professional ethics and correct ideological values. Therefore, Teachers need to integrate "curriculum ideological and political" education in pathology classrooms, and use this to reform and optimize pathology teaching, thereby comprehensively improving the quality of pathology teaching in my country and training more high-quality professional medical talents.

Keywords: Pathology; Curriculum Ideology; Teaching Reform

"Curriculum Ideology" is a new teaching concept based on cultivating outstanding professionals who have the correct values and understand self-dedication and sacrifice for the current social development. It is based on traditional education and teaching, strengthens ideological and political education, and combines professional knowledge to have a positive impact on students in a subtle way. It is more efficient than traditional separate ideological and political teaching methods. Therefore, based on many years of college pathology teaching experience, the author first analyzed the necessity of integrating "curriculum ideology" into pathology classroom teaching based on the actual teaching situation, and proposed some targeted teaching reform measures to achieve this. The effective integration of "curriculum ideology" in pathology teaching will comprehensively improve the quality of pathology teaching and promote the improvement of students' comprehensive ability.

\section{The necessity analysis of incorporating "curriculum ideology and politics" in pathology class}

Pathology is the main course of medical science, and its course content covers a wide range of knowledge, and many knowledge points are highly abstract. Therefore, in order to better educate and teach, teachers have for a long time basically put the focus of teaching on the learning of basic knowledge, but ignores the ideological and political education of students, which makes some students not clear their own learning goals, which greatly reduces The motivation to learn pathology. Therefore, the integration of "curriculum ideology" in the pathology classroom has a very positive effect on improving the quality of pathology teaching. First, it is an important way to realize "teaching and educating people". According to the content of the new curriculum teaching reform, schools not only need to teach students various knowledge, but also encourage students to establish correct life values and improve their own personality. The implementation of "curriculum ideology" is an important way to achieve this teaching goal. Second, it can train students to form good professional qualities. At present, the relationship between doctors and patients in our country is relatively tense. Students can further form good professionalism through "curriculum ideological and political", lay a good foundation for future work, and strive to become a medical worker serving the people. Finally, it can encourage students to develop a learning attitude that is hardworking and hardworking. Nowadays, people's material life is becoming more and more Copyright (C) 2020 Ningbo Huang

doi: $10.18282 /$ le.v9i7.1488

This is an open-access article distributed under the terms of the Creative Commons Attribution Non-Commercial License

(http://creativecommons.org/licenses/by-nc/4.0/), which permits unrestricted non-commercial use, distribution, and reproduction in any medium, provided the original work is properly cited. 
abundant, and college students are more free to learn in school, so they are more strongly influenced by external factors. Therefore, the implementation of "curriculum ideological and political" teaching in teaching can improve students' self-control Guide students to form correct learning attitudes and concepts, and help students to better complete professional courses.

\section{The exploration of implementing the teaching reform of "curriculum ideology and politics" in pathology teaching}

\subsection{Incorporate patriotism education into the teaching of pathology courses}

Our country is currently undergoing "great changes unseen in a century." In order to cultivate professional talents that meet the needs of social development, teachers should vigorously promote the great patriotism in classroom teaching, and try to make students form the great Chinese nation in their minds. The goal of rejuvenation and learning. For example, in the course of pathology teaching, teachers can combine the development history of China's people's health care construction since the founding of the People's Republic of my country, and use detailed data support to let students deeply understand my country's efforts to improve people's health conditions, so as to deepen students. A sense of identity with national policies and a sense of pride in democracy, and then more efforts to devote themselves to pathology learning, effectively improving the effectiveness of pathology classroom teaching.

\subsection{Incorporate scientific spirit concepts into pathology course teaching}

The most taboo thing in medical studies is speciousness. Therefore, teachers should incorporate scientific spiritual concepts into actual teaching, allowing students to dig deep into the core of the knowledge content, so as to learn one by one and learn one by one. In addition, in actual teaching, teachers should insist on taking students as the teaching center, guiding students to proceed from reality, cultivating students' scientific thinking methods of seeking truth from facts, and strengthening the application of experimental teaching. While improving students' hands-on ability, students should have a deep understanding of science. The importance of spirit in pathology learning.

\subsection{Incorporate humanistic education into pathology course teaching}

Pathology is a key subject that all medical students need to study. Therefore, this means that most students will be engaged in medical work. In the current complex social environment, in addition to teaching students to have solid basic knowledge, colleges and universities should also provide students with humanistic education, cultivate students to have good "medical ethics" and professionalism, and lay a solid foundation for future work. For example, in the teaching of pathology, teachers can appropriately discuss the concept of "death" that is elusive, so that students can understand that no matter how advanced medicine is today, many patients still cannot be exempt from "death". Therefore, medical students should not only master the "hard skills", but also think about problems from the perspective of the patient, learn to care for and enlighten the patient, reduce the patient's ideological pressure, and build a good doctor-patient relationship.

\subsection{Integrate social responsibility education into pathology course teaching}

Combining years of medical teaching experience, we can clearly understand that the quality of a doctor is not only the level of his own medical skills, but more importantly, whether the doctor has a sense of social responsibility to "save the dead and heal the wounded". Therefore, offline social practice activities should be vigorously promoted in pathology teaching, and students should be encouraged to participate in public medical treatment, and through personal experience, feel the importance of the responsibility of medical workers, so as to encourage themselves to study hard and continue to reflect. Practice the social problems encountered in learning, in order to stimulate students' sense of social responsibility and improve their comprehensive quality.

\section{Concluding remarks}

Implementing "curriculum ideology" in pathology teaching is an important way to achieve "teaching and educating people". It can subtly allow students to strengthen their national pride, correct their learning attitude, improve their professional quality, and effectively improve The quality of pathology teaching in my country has cultivated many 
high-quality medical talents with excellent theoretical skills and high medical ethics for the society and the country.

\section{References}

1. Yang Shaofen, Li Peiqin, Lin Sini. Exploration of the teaching reform of "Course Ideological and Political" in Pathology[J]. Journal of Molecular Imaging, 2019, 42(02):143-145.

2. Lin Jin, Tang Fenghua, Xu Ying. Exploration of the Ideological and Political Teaching Path of "Pathology" Course in Higher Vocational Colleges [J]. Education Teaching Forum, 2020, 000(020):103-105.

3. Li Bo, Qu Yuan, Xu Jing. Exploration and practice of ideological and political teaching reform integrated into professional courses[J]. Science and Technology Wind, 2020, No.417(13):83-83. 